\title{
Intensification of Thermal Convection near Electric Devices using Flat Screens - Computer Modelling
}

\author{
S. Czapp ${ }^{1}$, M. Czapp ${ }^{2}$ \\ ${ }^{1}$ Gdansk University of Technology, \\ ul. Narutowicza 11/12, 80-233 Gdansk, Poland \\ ${ }^{2}$ Koszalin University of Technology, \\ ul. Raclawicka 15-17, 75-620 Koszalin, Poland \\ s.czapp@ely.pg.gda.pl
}

\begin{abstract}
Intensification of natural thermal convection near electric devices is possible by application of additional elements as screens creating convection canals close to the device. In the earlier authors paper the results of the analysis of thermal convection with the use of only one additional screen close to the electric device were presented. This paper presents computer modelling of thermal convection when two screens near the electric device are implemented. One of the screen is a wall close to the electric device.
\end{abstract}

Index Terms-Electric devices, current-carrying capacity, heat transfer, thermal convection, thermal analysis.

\section{INTRODUCTION}

Effective heat transfer to the environment from electric devices is critical for their safe and economic operation. Intensive heat transfer is required for increasing currentcarrying capacity of electric devices. Heat transfer can occur in a natural (free) or forced (artificial) way. Forced convection is generally obtained by the use of air motion generators - ventilators. This is the heat transfer method of a relatively high effectiveness. Unfortunately, periodic verification is then necessary and energy supply incurs additional costs. The natural convection-based heat transfer methods are characterized by lower energy efficiency but have certain advantages [1]-[7].

Convective heat transfer intensity depends on air velocity and air temperature in the proximity of electric device surface. Fig. 1 presents typical variation of the above mentioned parameters [8].

The velocity profile $w_{\mathrm{h}}$ can be described on the base of the momentum balance equation

$$
\mu \frac{d^{2} w_{\mathrm{h}}}{d x^{2}}=-g\left(\rho_{\propto}-\rho\right)=-g \rho_{\propto} \beta v_{\mathrm{s}}\left(1-\frac{x}{\delta}\right)^{2},
$$

where $g$ - gravitational acceleration $\left(9,81 \mathrm{~m} / \mathrm{s}^{2}\right), \rho_{\propto}-$ ambient air density $\left(\mathrm{kg} / \mathrm{m}^{3}\right), \rho$ - local air density $\left(\mathrm{kg} / \mathrm{m}^{3}\right)$,

Manuscript received February 6, 2012; accepted April 16, 2012 $\beta$ - coefficient of air expansion (1/273), $v_{\mathrm{s}}$ - temperature increment, $\delta$ - boundary layer thickness, $\mathrm{x}-$ distance from the surface.

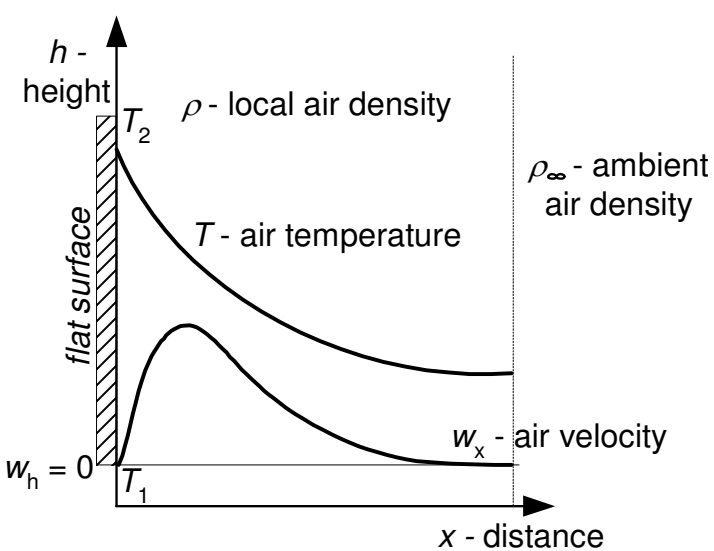

Fig. 1. Air velocity $w_{\mathrm{h}}$ and air temperature $T$ variations near flat surface natural thermal convection.

The boundary layer thickness can be evaluated by the following expression

$$
\delta=4,23\left(\frac{\mu \lambda h}{c_{\mathrm{p}} g \rho_{\propto}^{2} \beta v_{\mathrm{s}}}\right)^{0,25} .
$$

where $\mu$ - dynamic viscosity of air, $\lambda$ - thermal conductance coefficient of thermal conductivity of air $(\mathrm{W} / \mathrm{mK}), c_{\mathrm{p}}-$ specific heat $(\mathrm{J} / \mathrm{kgK})$.

The solution of the expression (1) can be presented in the following form

$$
w_{\mathrm{h}}=\frac{g \delta^{2} \rho_{\propto} \beta \vartheta_{\mathrm{s}}}{\mu} \cdot \frac{x}{\delta}\left\{\frac{1}{12}\left[1-\left(\frac{x}{\delta}\right)^{3}\right]-\frac{1}{3}\left[1-\left(\frac{x}{\delta}\right)^{2}\right]+\frac{1}{2}\left(1-\frac{x}{\delta}\right)\right\}
$$

Amount of heat $Q$ which is transferred from the flat surface depends on the mass flow rate of the air convection

$$
Q=f\left(\dot{m}, \Delta T, c_{\mathrm{p}}\right),
$$


where $\dot{m}$ - mass flow rate $(\mathrm{kg} / \mathrm{s})$ depends on the air velocity and temperature field, $\Delta T=T_{2}-T_{1}$.

Authors of this paper examine the possibility of natural convection intensification by forming air temperature field and air velocity close to the surface of electric device. This intensification can be obtained by the use of stationary screens near the device. Earlier paper [9] presented natural convection intensification by the use of only one screen. In this paper, computer modelling of the heat transfer for the example configuration of electric device with two screens is presented. One of the screens is a wall close to the electric device. For computer modelling, the Ansys/Flotran code was employed.

\section{ElECTRIC DEVICE WITH TwO SCREENS}

The analysis - similarly to the previous studies [9] - was carried out on a simplified electric device model $(145 \times 115 \mathrm{~cm})$ emitting the heat to the environment. Now the heat is emitted from two flat surfaces of the device - electric device is moved from a wall. The model diagram is shown in Fig. 2. The assumed temperature of those surfaces is $328 \mathrm{~K}$ $\left(55^{\circ} \mathrm{C}\right)$ and the environment (ambient) temperature is $293 \mathrm{~K}$ $\left(20^{\circ} \mathrm{C}\right)$. The distance of each screen to the heat emitting surface is equal to $x=4 \mathrm{~cm}$. This is the optimum distance between the electric device and the screen indicated in [9].

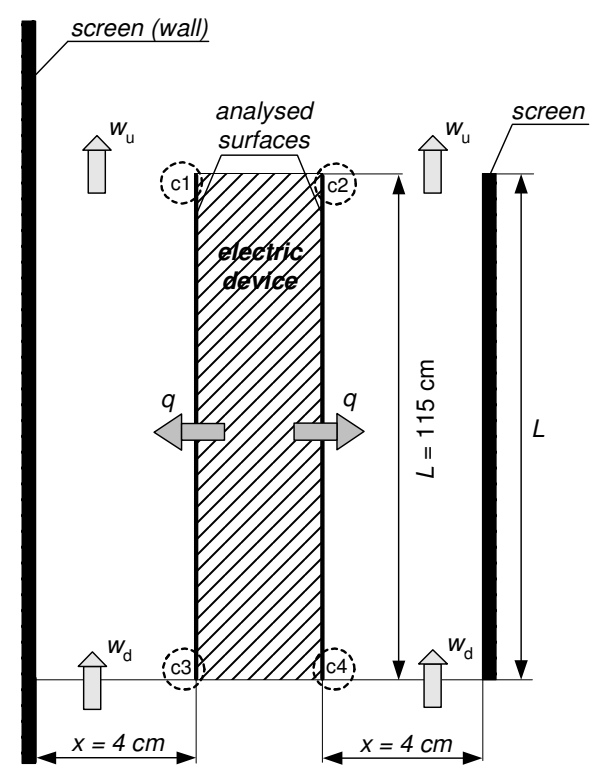

Fig. 2. Diagram of the analysed example; $q$ - heat flux generated by the analysed electric device surfaces, $w_{\mathrm{d}}-$ air velocity at the system inlet, $w_{\mathrm{u}}$ air velocity at the system outlet, $L$ - electric device and right screen height, $x$ - horizontal distance from the analysed electric device surface to the screens, c1, c2, c3, c4 - consecutive number of corner.

Simulations of the air temperature fields (Fig. 3) and air velocity fields (Fig. 4) were carried out with the Ansys software for the cases of arrangement without screens and with screens at a distance of $x=4 \mathrm{~cm}$ from the analysed electric device surfaces. Comparison between Fig. $3 \mathrm{a}$ and Fig. $3 \mathrm{~b}$ indicates that more intensive air motion occurs in the arrangement with screens, which has a positive impact on the heat transfer to environment. Similar conclusion flows from comparing Fig. 4, (a) and Fig. 4, (b).

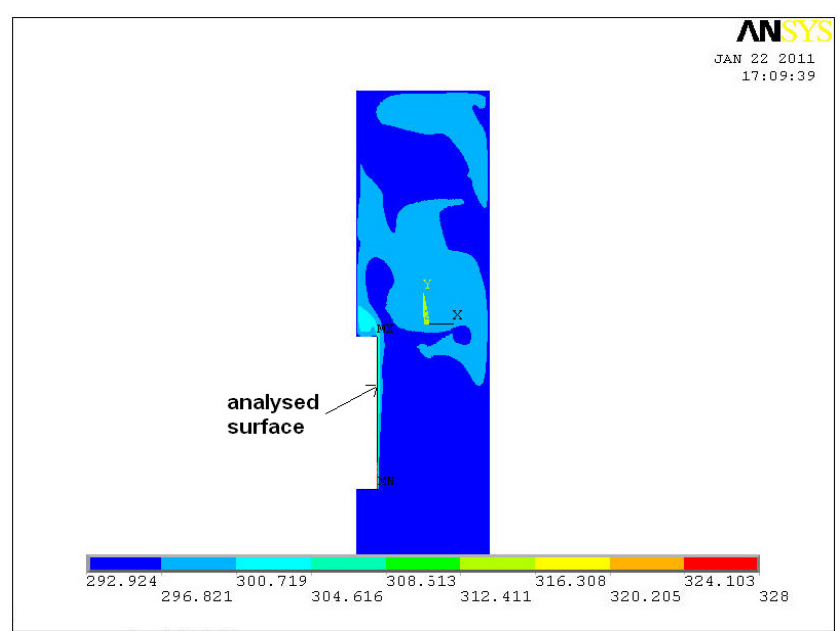

a)

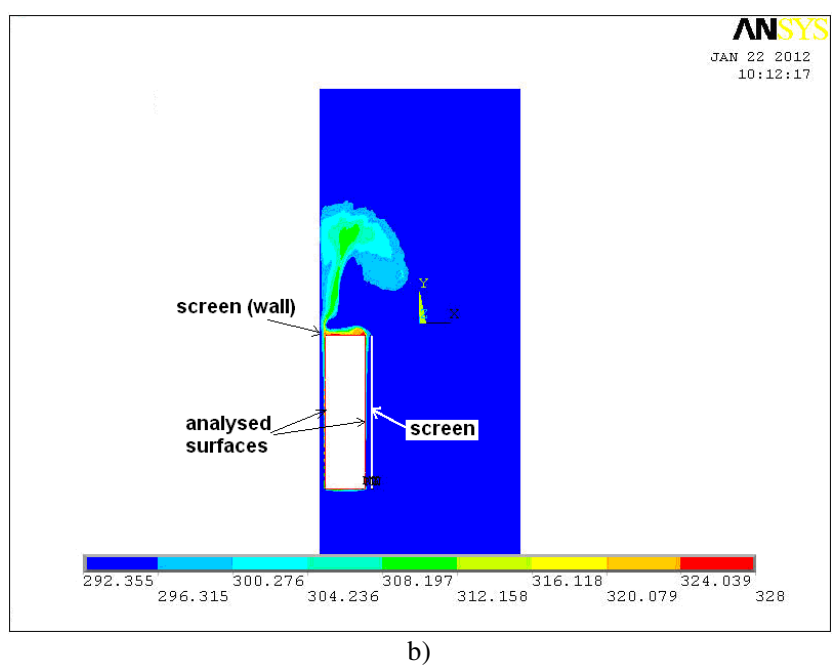

Fig. 3. Air temperature fields - results of simulation investigations of the analysed surfaces: a) without screen [9], b) with two screens at a distance of $x=4 \mathrm{~cm}$ (at the both sides of the electric device).

Fig. 5 presents enlarged parts of the electric device (upper part and bottom part) and air velocity vectors close to the surfaces. Such detailed computer analysis enables to indicate the direction of air velocity vectors.

Results of detailed computer simulation presented in Fig. 5a reveal the "chimney effect". This effect amplifies intensity of thermal convection and enables to increase the current-carrying capacity of electric devices.

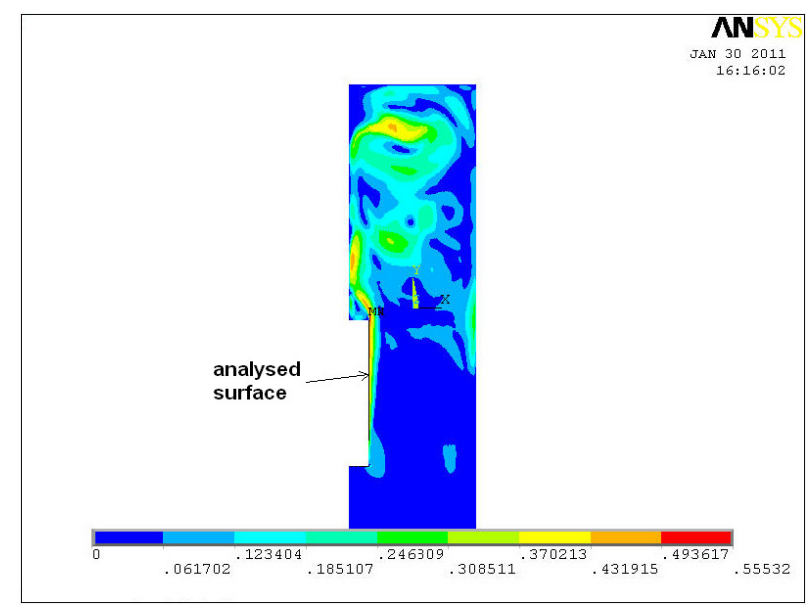

a) 


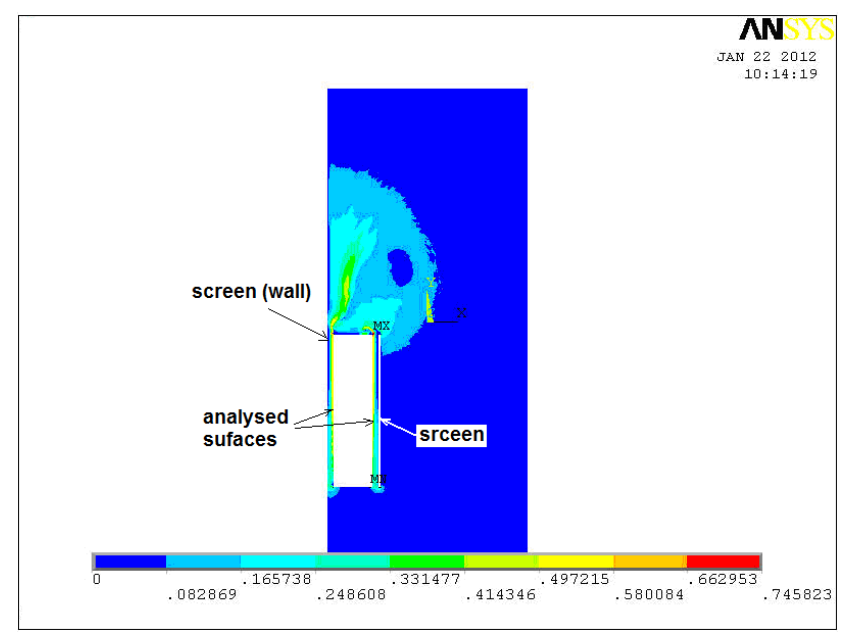

b)

Fig. 4. Air velocity fields - results of simulation investigations of the analysed surfaces: a) without screen [9], b) with two screens at a distance of $x=4 \mathrm{~cm}$ (at the both sides of the electric device).

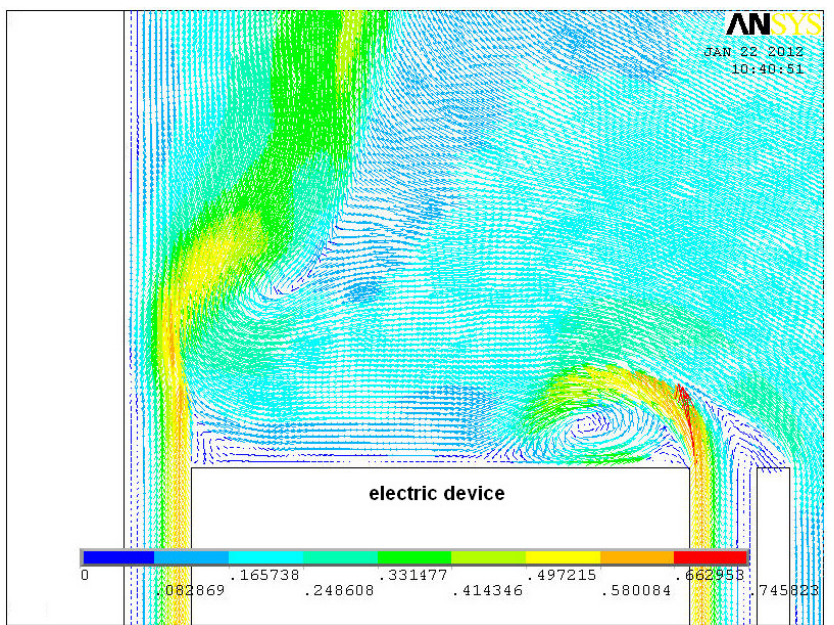

a)

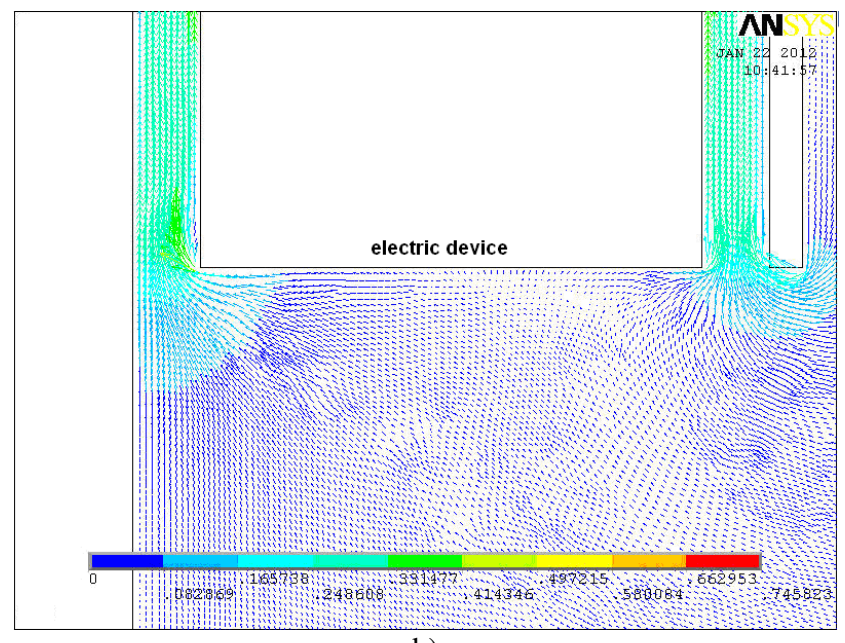

b)

Fig. 5. Air velocity distribution: a) at the top of the electric device, b) at the bottom of the electric device; arrangement with two screens.

Comparison of air velocity vectors close to each canal allows to state that the effect of particular canal is not identical. The arrangement is asymmetrical - the right-side screen is shorter than the left-side. The right-side screen and its adjacent canal enables to obtain higher air velocity than the left canal.

The traces in Fig. 6 are the confirmation for the above conclusion. The maximum value of air velocity (Fig. 6b) is higher in the upper right corner (the right-side screen) than the upper left corner (the left-side screen).

Higher air velocity makes that temperature in the rightside canal decrease higher with increasing horizontal distance between the electric device surface and the screen, than in the left-side canal. Variation of air temperature in canals as a function of horizontal distance between the electric device surface and the screen is presented in Fig. 7.

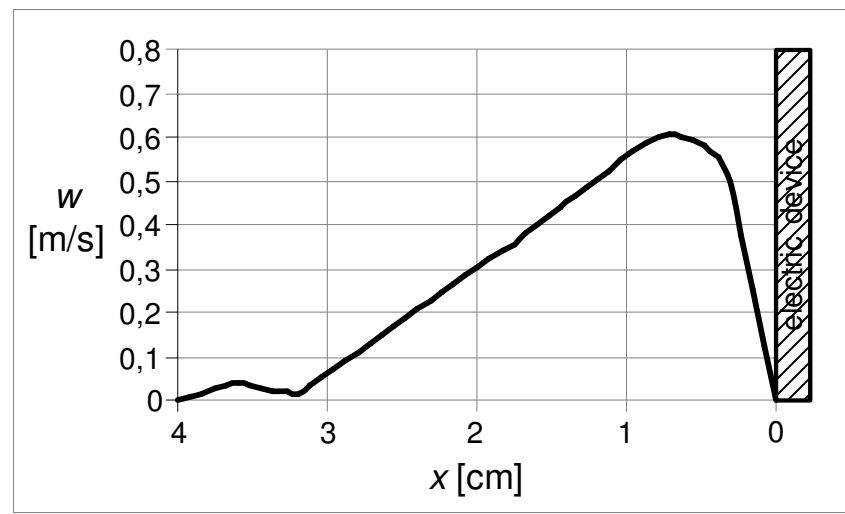

a)

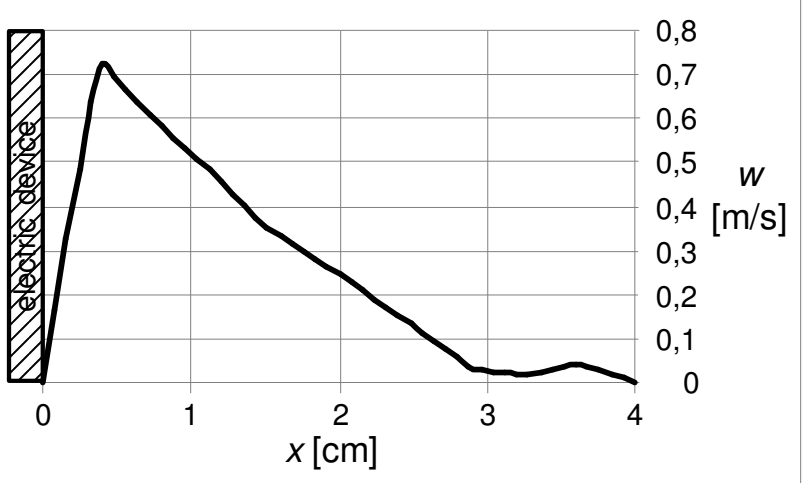

b)

Fig. 6. Air velocity $w$ as a function of distance $x$ from the surface: a) upper left corner $\mathrm{c} 1, \mathrm{~b}$ ) upper right corner $\mathrm{c} 2$; each screen at a distance of $x=4 \mathrm{~cm}$.

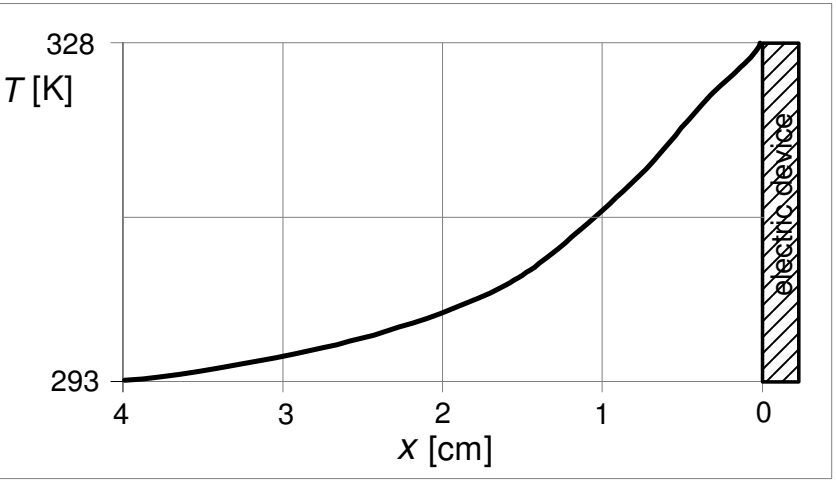

a) 


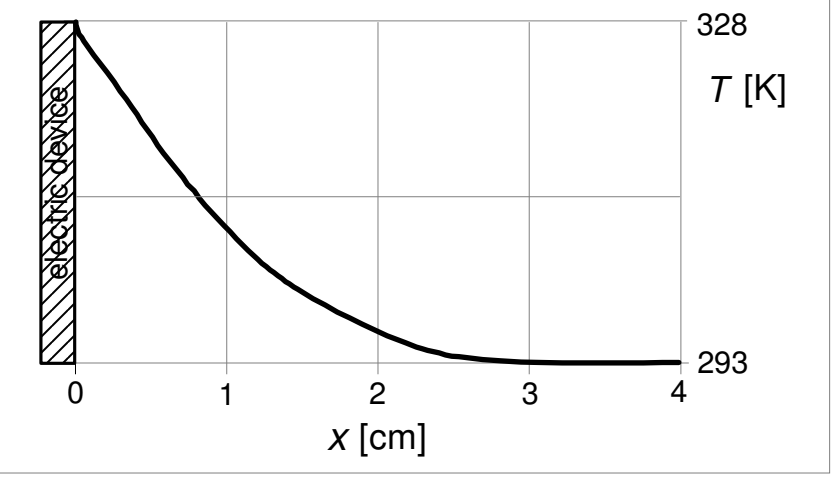

b)

Fig. 7. Air temperature $T$ as a function of distance $x$ from the surface: a) upper left corner $\mathrm{c} 1, \mathrm{~b}$ ) upper right corner $\mathrm{c} 2$; each screen at a distance of $x=4 \mathrm{~cm}$.

\section{CONCLUSIONS}

Performed computer analysis and modelling present thermal convection process along flat surfaces of the example electric device. Flat screens applied near electric device make thermal convection process more intensive in comparison to the arrangement without screens. Detailed analysis of air velocity vectors can be supportive for searching methods of further increasing of natural thermal convection. The height of screens near electric devices is important for intensification of natural thermal convection.

\section{REFERENCES}

[1] H. Brakelmann, G. Anders, "Increasing Ampacity of Cables by an Application of Ventilated Pipes", in Proc. of the $39^{\text {th }}$ Industry Applications Conference, 2004, vol. 4, pp. 2288-2295.

[2] Low-voltage electrical installations - Part 5-52: Selection and erection of electrical equipment - Wiring systems, IEC 60364-552:2009, 2009

[3] F. Leon, Calculation of Underground Cable Ampacity, CYME International, T\&D, 2005.

[4] C. M. Liao, C. L. Chen, T. Katcher, "Thermal Analysis for Design of High Performance Motors", in Proc. of the Sixth Intersociety Conference on Thermal and Thermomechanical Phenomena in Electronic Systems (ITHERM 98), 1998, pp.424-433. [Online]. Available: http://dx.doi.org/10.1109/ITHERM.1998.689596

[5] Y. Oner, "Thermal Analysis of the Three-Phase Induction Motor and Calculation of its Power Loss by using Lumped-Circuit Model", Elektronika ir Elektrotechnika (Electronics and Electrical Engineering), no. 8, pp. 81-84, 2010.

[6] D. A. Staton, A. Cavagnino, "Convection Heat Transfer and Flow Calculations Suitable for Analytical Modelling of Electric Machines", in Proc. of the IEEE 32 ${ }^{\text {nd }}$ Annual Conference on Industrial Electronics (IECON), 2006, pp. 4841-4846.

[7] M. Szpakowska, M. Czapp, "Investigation of Intensity Convective Heat Transfer on the Isothermal Surface", XIII Sympozjum Wymiany Ciepla i Masy, Koszalin, Darlowko, Poland, 2007, vol. 2, pp. 993 997.

[8] S. Wiśniewski, T. G. Wiśniewski, Wymiana ciepta. WNT, Warszawa, 1994. (in polish).

[9] S. Czapp, M. Czapp, "Computer-aided analysis of thermal convection near electric devices", Elektronika ir Elektrotechnika (Electronics and Electrical Engineering), no. 3, pp. 21-24, 2011. 